\title{
Spectrum of Congenital Heart Disease in Neonates Admitted in an Intermediate Care Unit of a Tertiary Level Hospital
}

\author{
Chapagain $\mathrm{RH}^{1}$, Shrestha $\mathrm{N}^{2}$, Kayastha $\mathrm{M}^{3}$, Shakya $\mathrm{S}^{4}$, Adhikari $\mathrm{K}^{5}$, Shrestha $\mathrm{SM}^{6}$
}

\begin{abstract}
Introduction: Congenital Heart Disease is the most common cause of major congenital anomalies accounting $28.0 \%$, representing a major global health problem. Prevalence of Congenital Heart Disease is 1.3 per 1000 in school children of Nepal. Material and Methods: A cross sectional prospective study was carried out in the neonatal intermediate care unit of Kanti Children's Hospital, Nepal from Jan 2016 until Dec 2016 to see the spectrum of CHD. Results: Out of admitted 831 neonates, 85 were found to have CHD with prevalence of 102.28 per 1000 admitted neonate. Respiratory distress was the commonest symptom $(51.8 \%)$ followed by cyanosis $(11.8 \%)$ and reluctant to feed $(10.6 \%)$ at presentation. ASD was the commonest $(87.1 \%)$ cases followed by PFO $23.5 \%$, PDA $21.2 \%$, Complex congenital heart disease $11.8 \%$ and TOF $1.2 \%$. Cleft lip and Cleft Palate was found in $5.9 \%$, Down's syndrome $3.5 \%$ of cases, polydactyly and syndactyly was detected in $2.4 \%$ newborn with $\mathrm{CHD}$. The mode of delivery was spontaneous in $71.8 \%$ followed by Elective LSCS were $14.1 \%$ and Emergency LSCS were 9.4\%. Conclusions: Prevalence of $\mathrm{CHD}$ was the 102.28 per 1000 neonates admitted in NIMCU. Atrial Septal Defect was the commonest congenital heart diseases. Cleft lip and Down's syndrome were the most extra cardiac anomaly associated with CHD. Respiratory distress was the commonest presentation of $\mathrm{CHD}$ for hospital admission.
\end{abstract}

Key words: Congenital, Heart disease, Prevalence

\section{Introduction}

C ongenital heart disease (CHD) is the most common cause of major congenital anomalies accounting $28.0 \%$, representing a leading global health problem with prevalence in neonate of be $5-8 / 1000^{1,2,3,4}$. Studies done in Pakistan and India showed a prevalence rate of up to $4 / 1000$ live births ${ }^{5,6}$. Literature review could not find any prevalence study in neonates of Nepal as such, but some showed that the prevalence of $\mathrm{CHD}$ in school childrenwas 1.3 per 1000 and 5.8 per 1000 hospitalized patients ${ }^{7,8}$. Worldwide the prevalence of $\mathrm{CHD}$ has increased substantially from $<1$ per 1,000 live births in 1930 to 9 per 1,000 live births in recent years due to changes in diagnostic methods and screening modalities rather than representing a true
${ }^{1}$ Dr. Ram Hari Chapagain, MBBS, MD, Senior Consultant Paediatrician, Kanti Children's Hospital and Assistant Professor of Paediatrics National Academy of Medical Sciences (NAMS), ${ }^{2}$ Dr. Needa Shrestha, MBBS, MD, Paediatrican, Kanti Children's Hospital, Kathmandu, ${ }^{3}$ Dr. Madhusudhan Kayastha, MBBS, MD, Paediatrican, Kanti Children's Hospital, Kathmandu, ${ }^{4}$ Dr. Sheelendra Shakya, Cardiologist, Manmohan Cardiothoracic Vasular and Transplant Center, Institute of Medicine, Tribhuvan University Teaching Hospital, Kathmandu, ${ }^{5} \mathrm{Ms}$. Kimat Adhikari Team Leader, Central Region FHI 360, Kathmandu, ${ }^{6} \mathrm{Mr}$. Sushan Man Shrestha, MBBS, MD, Lecturer, Department of Community Medicine, Institute of Medicine, Tribhuvan University Teaching Hospital, Kathmandu, Nepal.

\section{Address for correspondence \\ Dr. Ram Hari Chapagain, MBBS, MD \\ Senior Consultant Paediatricain, \\ Kanti Children's Hospital \\ Tel No; 977-9841409080 \\ E-mail: chapagainrh2007@gmail.com}

Acknowledgements: We would like to thank all the staff of NIMCU who helped during this study and all neonates along their mother for completion of this study.

Funding: Nil

Conflict of Interest: None

Permission from IRB: Yes

\section{How to cite}

Chapagain RH, Shrestha N, Kayastha M, Shakya S, Adhikari K, Shrestha SM. Spectrum of Congenital Heart Disease in Neonates Admitted in an Intermediate Care Unit of a Tertiary Level Hospital. J Nepal Paediatr Soc 2017;37(2):174-177.

doi: http://dx.doi.org/10.3126/jnps.v37i2.17623

This work is licensed under a Creative Commons Attribution 3.0 License. 
increase ${ }^{9,10}$. Thus, the aim of this study was to find out the spectrum and prevalence of CHD presented in a Neonatal Intermediate care unit of a tertiary care paediatric hospital of Nepal.

\section{Material and Methods}

This prospective study was carried out over a period of one year from January 2016 until December 2016 among the admitted neonate in the Neonatal Intermediate Care Unit (NIMCU) age ranging from newborn to 28 days. A thorough clinical examination was carried out within first 24 hours of admission. Congenital Heart Disease (CHD) was suspected in the presence of following criteria defined by Mitchell et. $\mathrm{al}^{1}$. Presence of cardiac murmur, presence of cyanosis or feeding difficulty only, cyanosis associated with feeding difficulty, presence of congestive heart failure or failure to thrive. Detailed history was collected from parents or attendant regarding family history of congenital heart disease in siblings, parents. The questionnaire also enquired about; significant history of ingestion of drugs, hormone, exposure to radiation, history of fever with rash prior six months of conceptions and in 1st trimester, maternal age and parity of the mother. The birth weight, age, sex and gestational age of babies were also recorded. All suspected patients were investigated by doing a chest X-ray and 2D, M-mode echocardiography with colour Doppler. Additional screening for babies of diabetic mothers, all babies with Down's syndrome and babies with congenital malformations were alsoscreened.

\section{Results}

There were 831 neonates admitted during the study period out of which 85 were found to have CHD. The prevalence was 102.28 per 1000 admitted neonates, seventy six $(89.41 \%)$ were term and $9(10.58 \%)$ were preterm.

Table I shows respiratory distress was the commonest symptom (51.8\%) followed by cyanosis $(11.8 \%)$ and reluctance to feed (10.6\%). Other nonspecific and non-significant symptoms like fever, cough, tachypnoea etc were also noted.

Table 2 shows types of structural defect in newborns. Significant ones were ASD 87.1\%, PFO 23.5\%, PDA $21.2 \%$, ComplexCongenital Heart Disease in $11.8 \%$ and TOF in $1.2 \%$.

Significantly associated non-cardiac anomalies (Table 3) were also seen, like Cleft lip and Cleft Palate in $5(5.9 \%)$, Down's Syndrome in $3(3.5 \%)$, polydactyly and syndactyly were detected in $2(2.4 \%)$ new-borns andrenal anomaly was found in $1(1.2 \%)$ of the cases.
Table 4 shows pattern of risk factors in cases of babies with congenital heart disease. Maternal infection was noticed in $3(3.5 \%)$ cases. The commonest mode of delivery was spontaneous $(71.8 \%)$, Elective LSCS were done in $12(14.1 \%)$ and Emergency LSCS were done $8(9.4 \%)$.

Table 1: Presentation of congenital heart disease on admission

\begin{tabular}{lc}
\hline Presentation & No. of patients $(\mathbf{n}=\mathbf{8 5})$ \\
\hline Respiratory distress & $44(51.8)$ \\
\hline Cyanosis & $10(11.8)$ \\
\hline Reluctant to feed & $9(10.6)$ \\
\hline Others & $22(25.8)$ \\
\hline
\end{tabular}

Table 2: Types of structural defect in CHD in new-borns $(n=85)$

\begin{tabular}{lc}
\hline \multicolumn{1}{c}{ Types } & $\begin{array}{c}\text { Numbers } \\
\text { (n=85) }\end{array}$ \\
\hline ASD & $94(87.1)$ \\
\hline PDA & $18(21.2)$ \\
\hline VSD & $14(16.5)$ \\
\hline Myxomatus Valve & $14(16.5)$ \\
\hline Complex Congenital Heart Disease & $10(11.8)$ \\
\hline Pulmonary Stenosis & $5(5.9)$ \\
\hline Double outlet right ventricles (DORV) & $4(4.7)$ \\
\hline Persistent left superior venacava (PLSVC) & $4(4.7)$ \\
\hline Transposition of great Arteries (TGA) & $2(2.4)$ \\
\hline Atrio ventricular septal Defect (AVSD) & $2(2.4)$ \\
\hline Tetralogy of Fallots (TOF) & $1(1.2)$ \\
\hline Total Anomalous pulmonary venous & $1(1.2)$ \\
connection (TAPVC) & $1(1.2)$ \\
\hline Hypertrophic Cardiomayopathy &
\end{tabular}

Table 3: Associated non cardiac anomalies $(n=85)$

\begin{tabular}{lc}
\hline Non cardiac Anomalies & No of patients (\%) \\
\hline Cleft lip cleft palate & $5(5.9)$ \\
\hline Down's syndrome & $3(3.5)$ \\
\hline Polydactyly with syndactyly & $2(2.4)$ \\
\hline Renal Anomaly & $1(1.2)$ \\
\hline
\end{tabular}

Table 4: Maternal History and Mode of delivery

\begin{tabular}{lc}
\hline Maternal History & $\begin{array}{c}\text { Total number of mothers } \\
(\mathbf{n}=\mathbf{8 5})\end{array}$ \\
\hline Maternal infection & $3(3.5)$ \\
\hline Antipyretic & $1(1.2)$ \\
\hline Mode of delivery & \\
\hline spontaneous & $61(71.8)$ \\
\hline Elective LSCS & $12(14.1)$ \\
\hline Emergency LSCS & $8(9.4)$ \\
\hline Vacuum & $4(4.7)$ \\
\hline
\end{tabular}

LSCS $=$ Lower Section Caesarean Section 


\section{Discussion}

Congenital heart disease has already been recognized as one of the important risk factor for neonatal morbidity. Ferencz et. al. reviewed seven major studies from Europe and North America and concluded that confirmed $\mathrm{CHD}$ prevalence had been remarkably constant at 4/1000 live births over 40 years time span from 1940-198011. A study done in tertiary centre inKathmandu, Nepal showed the incidence of CHD to be 5.8 per 1000 hospitalized patients and a community study showed the prevalence of Rheumatic Heart disease and Congenital Heart Disease combined were 1.2 per 1000 and 1.3 per 1000 in school children ${ }^{12,13}$. The present study showed theratio of 1 per 9.7 neonate admitted in the NIMCU. This could beattributed to the neonate having $\mathrm{CHD}$ is prone to trivial illnesses and being admitted to hospital as compared to a normal neonate.

Clinically Respiratory distress (51.8\%) was the commonest presenting system followed by Cyanosis $(11.8 \%)$ and reluctant to feed (10.6). Similar observation were alsodetected by others ${ }^{9,12,14}$.

The commonest congenital heart disease in our study was ASD (87.1\%) which was similar to the observation by Rahman $S$ et.al and Siddique FM 15,16 yet our study did not correlate to the other studies which shows VSD as the commonest congenital heart defect $^{1,12,14}$.

\section{References}

1. Mitchell SC, Korones SB, Berendes HW. Congenital heart disease in 56, 109 births. Incidence and natural history. Circulation 1971;43:323-32.

2. Dolk H, Loane M, Garne E. For the European Surveillance of Congenital Anomalies (EUROCAT) working Group. Congenital heart defects in Europe: prevalence and perinatal mortality, 2000-2005. Circulation 2011;123:841-9.

3. Samanek M, Voriskova M. Congenital heart disease among 815,569 children born between 1980 and 1990 and their 15 year survival: a prospective Bohemia survival study. Pediatr Cardiol 1999;20:411-17.

4. Wren C, Richmond S, Donaldson L. Presentation of congenital heart disease in infancy: implications for routine examination. Arch Dis Child Fetal Neonatal Ed. 1999; 80:49-53.

5. Hassan I, Haleem AA, Bhutta ZA. Profile and risk factors for congenital heart disease. J Pak Med Assoc 1997;47:78-81
Our study showed significant association of non cardiac anomalies and somatic anomalies in 11(12.9\%) cases, among which cleft lip cleft palate,Down's syndrome, polydactyly with syndactyly and renal anomaly were the commonest.Studies done by Hofman, Sah GS et.al and Rahaman S et.al. also showed similar results ${ }^{13,15,17}$.

Maternal diseases like diabetes mellitus, maternal infection, hypertension and drugs could affectthe increase occurrence of CHD in neonates. Our study found that only $3.5 \%$ mothers had history of infections during pregnancy and only one mother had history of using antipyretic drugs.

Neonates with CHD are more prone to develop intrauterine foetal distress that could mean frequent LSCS either elective or emergency during delivery but our study showed the frequency of normal delivery higher than the LSCS.

\section{Conclusions}

Our observations show, prevalence of CHD was the 102.28 per 1000neonates admitted in NIMCU. ASD was the commonest CHD. Cleft lip and Down's syndrome were the most extra cardiac anomalies associated with $\mathrm{CHD}$ and that respiratory distress and cyanosis were the commonest presentation of CHD.

6. Chadha SL, Singh N, Shukla DK. Epidemiological study of Congenital heart disease. Indian $J$ Pediatr 2001;68:507-10.

7. KC MB, Sharma D, Shrestha MP. Prevalence of rheumatic and congenital heart disease in school children of Kathmandu valley in Nepal. Indian Heart $J$ 2003;55(6):615-8.

8. Shah GS, Singh MK, Pandey TR, Kalakheti BK, Bhandari GP. Incidence of congenital heart disease in tertiary care hospital. Kathmandu Univ Med J2008;6(1):33-6

9. Khali A, Agarwal R, Thirupuran S. Prevalence of congenital heart disease among hospital live births in India. Indian Pediatr 1994; 31:519-26.

10. Mollah MAH, begum NA, Islam MN. Clinical profile of congenital heart diseases (CHD): an Analysis of 218 cases. Bangladesh Heart J 2002;17:62-7.

11. Ferencz C, Rubin JD, Meconter RJ. Congenital Heart Diseases. Prevalence at live birth. The Baltimore Washington infant study. Am J Epidemiol 1985;121:3136. 
12. Shah GS, Singh MK, Pandey TR, Kalakheti BK, Bhandari GP. Incidence of congenital heart disease in tertiary care hospital. Kathmandu Univ Med $J$ 2008;6(1):33-6.

13. KC MB, Sharma D, Shresth MP et al, Prevalence of rheumatic and congenital heart disease in school children of Kathmandu valley in Nepal, Indian Heart $J$ 2003;55(6):615-8.

14. Islam MN, Hussain MA,Khaleque MA,Das MK,Khan $\mathrm{MRH}$,Bari MS and et al. Prevalence of congenital Heart Disease in Neopnatal in a Tertiary Level Hospital. NJMS 2013;2(2):91-95.
15. Rahman S, Ahmed MN, Rahmatullah KHI. The prevalence of congenital heart diseases diagnosed by Non-invasive technique- Ten years study in Bangladesh. DS (Child) HJ 1992;8:5-15.

16. Siddique FM, Kamal SMM, Huq KMHSS. Clinical presentation of congenital heart diseases in hospitalized patients. Bangladesh Heart J 1989;4:1317.

17. Hoffman JIE. Congenital heart disease: Prevalence and inheritence. Pediatr Clin North Am 1990;37:25-43. 